\title{
Measurement of the Economic Benefit of Urban Rail Transit Station Under the Mode of Comprehensive Development
}

\author{
HAN Chenlin \\ School of Economics and Management, Beijing Jiaotong University, China \\ hanchenlin_15@163.com
}

Keywords: Rail transit, Investment and financing, Comprehensive development

\begin{abstract}
As the end of 2015, there are 25 cities having finished urban rail transit construction in China, and the total length is 3293 kilometers. There are 40 cities building the urban rail transit, and the length will be more than 4000 kilometers. It is estimated that the total investment of urban rail transit construction will exceed 2 trillion yuan from 2016 to 2020. Most researchers put forward to draw upon experience of Hong Kong, Taiwan or learn from overseas experience on integrated development to absorb the private capital. Establishing the mathematical model and calculate the economic benefit of comprehensive development model. Assuming that Beijing subway line four use the comprehensive development model, the company will gain the biggest benefit when the average development scale of each station is $12540.42 \mathrm{~m}^{2}$, with the income of land development achieving 1.133 billion yuan, and the Beijing municipal government can save 1.29 billion yuan of demolition expenditure.
\end{abstract}

\section{Introduction}

Beijing urban line 1 is the first urban rail transit line of China, it was built in October 1969. In China, there had four cities been constructing the urban rail until the end of the 20th century. During this period, the construction of urban rail was small, and government could afford the financial demand easily, the investment and financing were not the big problems at that time. Since 2000, with the development of China, the construction of urban rail transit has increased rapidly, at the end of 2015, there have 110 urban rail lines in 25 cities been coming into service, the total length is 3293 kilometers. There are 40 cities building the urban rail transit, and the length is more than 4000 kilometers. Apparently, urban rail transit construction need more capital.

At present, the construction scale of urban rail network in China is much larger than before. Almost each urban rail corporate requires a large amount of capital supplement and financial subsidy from the local government each year. Taking the Beijing Infrastructure Investment Co., Ltd. (BIIC) for example, according to the contract, from 2008 to 2012 , BIIC has received 10 billion yuan each year as the capital supplement from Beijing government, and this number has increased to 15.5 billion yuan since 2013. Not only the capital supplement, But BIIC has received the financial subsidy from Beijing government, this number is more than 2 billion yuan each year. Other urban rail corporate is just like the BIIC, they also need huge financial support which is from government.

Under the huge financial pressure made by the construction of urban rail transit, many scholars began to study the urban-rail-station's land comprehensive development, hoping increasing the profit of the corporate by the comprehensive development. Just like the comprehensive development of Hong Kong and Taiwan, the model of their comprehensive development has be called TOD, TOD could recover some of the external benefit, and release the financial pressure of government.

How much the revenue of urban-rail-station's comprehensive development could make? How to decide the scale of comprehensive development? Based on the premise of urban-rail-station's comprehensive development, this paper builds a model to calculate the economic revenue and the scale of land-used. 


\section{Literature Review}

Many scholars think that the station comprehensive development could solve the financing problems of urban rail project. Cai Wei (2007) suggests that the government should transfer the development right to the corporate of urban rail, the latter could recover more external benefit for the social public [1]. Hao Cheng, Li Jing (2009) [2], Li YF, Shi SS Zhang (2014) [3] and others point out that China could reference TOD mode of Hong Kong. Considering the comprehensive development is a wide topic, the operation field of the corporate could cover tourism, ads, the real industry and retail business, and all those business could be applied to the urban rail station.

According to the evidence, price of the land which is near to the urban rail stations will increase rapidly with the operation of new urban rail line, many domestic and foreign scholars have carried on the empirical research to the phenomenon. Chan Wen et al. (2010) introduce the Xi'an Metro Line 2. During the research, they use the land price function method and regression analysis to measure the price change of real industry which was made by the urban rail line. In their paper, they find that the price of real industry shares a rapid increase, and the rising rate is decreasing with the distance being larger [4]. He Dan, Jin Fengjun (2013) use the regression model to measure the line 4 of the Beijing. The model shows that the price of land risen since the urban rail had been put into operation [5]. Needham (2015) think light rail construction will improve the efficiency of land use. At the same time, it will increase the price of land in the range of $0.5 \mathrm{~km}[6]$. There are many papers having analyzed the comprehensive development of urban rail station, and the main conclusion is true. With the building and operation of urban rail, the price of land and real industry share an increase obviously.

\section{Mode of TOD}

TOD is widely used in Hong Kong and Taiwan, the comprehensive development which is surrounding the station, could enhance the business density, as shown in Fig.1.

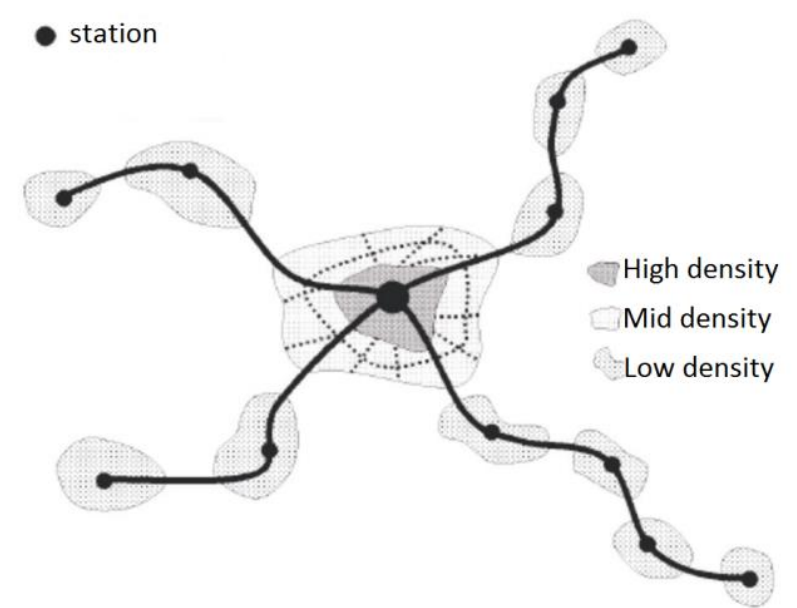

Fig 1 the spatial structure of TOD

According to Fig.1, when corporation design the urban rail stations, if the government considers the station comprehensive development, it could enhance the efficiency of land-use, build a more efficient city's spatial structure, and promote the sustainable development of urban.

Comprehensive development could attract the private capital to invest urban rail transit, which not only supports the transportation service, but also releases the financial pressure of government. And financial resource could be used in other public field, and enhance the efficient of public investment.

When it comes to society, the private capital could enter the field of urban rail transit through the mode of comprehensive development. As we all know, economists admit the private capital and market are much more effective than the government. On the process of investment and operation, the benefit is the most important thing for the social capital. For the sake of lower costs and higher profits, enterprises must choose the right management idea and improve business efficiency, which is good for the social function. 


\section{Model Design and Result Analysis}

This chapter will build the economic model of urban rail station's comprehensive development mode, with the Beijing Metro Line 4 as the case study followed.

Model Design. The first thing is to build the total benefit model.

$$
\begin{aligned}
& \text { Benefit }=T R-T C \\
& T C=\mathrm{n} x_{1} p
\end{aligned}
$$

$n$ means the number of urban rail station; $x_{1}$ means the scale of land use; $p$ means the price of land expropriation; $x_{1} p$ is the total land expropriation cost of each station.

$$
p_{1} / p_{2}=\left(y_{1} * x_{1}\right) /\left(y_{2} * x_{2}\right)
$$

The $p_{1}$ means total revenue of land-sale; $y_{1}$ means the unit price of land-sale; $x_{1}$ means the scope of land-sale; $p_{2}$ means total revenue of the real industry; $\mathrm{y}_{2}$ means the unit price of buildings; $x_{2}$ means the size of buildings.

$$
z=x_{2} / x_{1}
$$

According the equation (1) to equation (4), we can gain the equation (5) as follow.

$$
T R=n \int_{0}^{r} 2 \pi x_{1} y d x_{1}=n \int_{0}^{r} 2 \pi x_{1} z y_{2} p_{1} / p_{2} d x_{1}
$$

Result Analysis. Beijing Metro Line 4 started construction in August 2004, and put into operation in September 2009. The total length is $28.2 \mathrm{~km}$, which includes 24 stations. The total construction cost is 15.3 billion yuan, in the cost of which the Beijing government funded $70 \%$, the MTR Corporation invested the other $30 \%$.

During the construction process, the total cost of demolition is 1.29 billion yuan, the building demolition is 244.4 thousand $\mathrm{m}^{2}$. The cost of land acquisition is $5278.23 * 0.85=4486.49$ yuan $/ \mathrm{m}^{2}$. We need to transfer the price level from 2004 to 2014, and there is an important index, the major Chinese cities residential price index (CRLPI). Using CRLPI to adjust the price level, the value of $p$ is 50961.

$$
y_{2}=\alpha \ln x_{3}+\beta
$$

In this paper, assume the number of $z$ is 2 , according to the data published by the government, the value of $p_{1} / p_{2}$ is 0.232 , Fig. 2 shows the relationship of building price and distance.

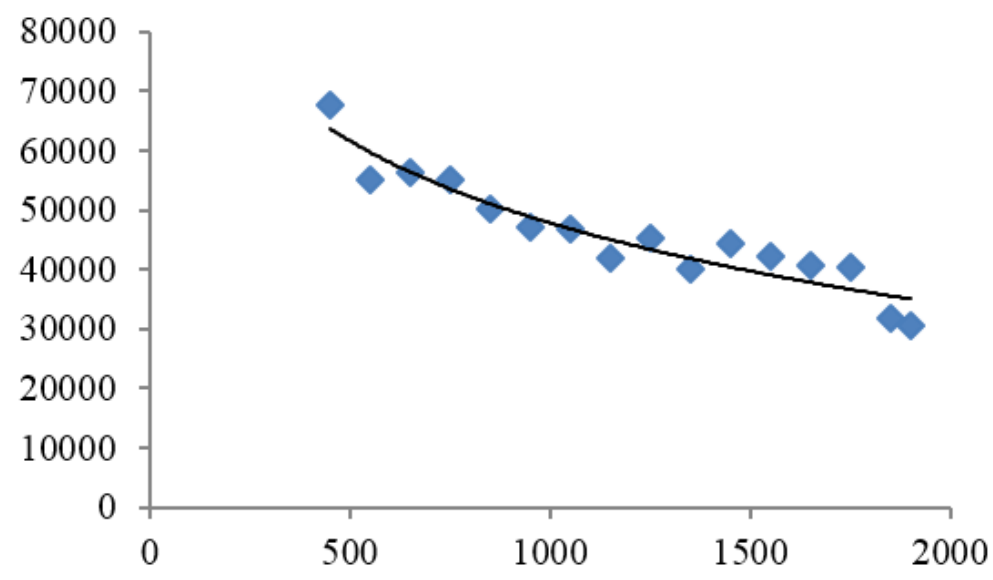

Fig 2 the relationship between building price and distance.

According to the data of Fig 2, $\alpha$ is -22898 , the $\beta$ is 204766, and we can calculate the equations.

$$
\begin{aligned}
& T R=-5312 n x_{1} \ln x_{1} / \pi+100323 n x_{1} \\
& B \text { enefit }=n\left(49362 x_{1}-5312 x_{1} \ln x_{1} / \pi\right)
\end{aligned}
$$

When the $x_{1}$ is 12540 , the $n$ is 17 , the Benefit is 1.133 billion yuan, it's the largest revenue of land comprehensive development. If the Beijing urban rail line four chooses land comprehensive development, the land income is 1.133 billion yuan, and the government could save the cost of demolition, that's be called internalize the external benefits. 


\section{Summary}

It's a serious issue to attract funds into the field of urban rail transit. But china's urban rail transit financing difficulties mainly lie in the large project investment, long construction period, high risk, and poor direct economic benefit.

Just as the other public infrastructure, urban rail transit creates the huge external benefits, but the corporate of urban rail couldn't share external benefits. As a result, private capital lacks investment motivation, and the construction mainly depends on the government financial investment.

This paper assumes that if Beijing Metro Line 4 chooses the mode of land comprehensive development, when the scale of land use is $12540.42 \mathrm{~m}^{2}$, the corporate could benefit 1.133 billion yuan, and the government could save a huge amount of relocation expenses. Land comprehensive development has been used in Shenzhen and Changsha, in the future, this kind of mode maybe widely used in China in order to attract more private funds.

\section{Acknowledgements}

This work was financially supported by Beijing Philosophy and Social Science Foundation (15JDJGA083).

\section{References}

[1] Cai Wei. Analysis on the Evolution Mechanism of the Investment and Financing System for Native Urban Mass Transit. Tongji University (2007).

[2] Hao Cheng, Li Jing. A Comparative Analysis of Financing Methods for Urban Mass Transit in Beijing, Hong Kong and New York. Research on Urban Rail Transit (2009).

[3] Li Yafei, Zhang Hong. Analysis on the Urban Rail Transit Financial mode. Financing Study (2014).

[4] Wen Chan, Chen Ying, Zhang Hui. Impact of Urban Rapid Rail Transit on House Prices. Journal of Jiangnan University (2010).

[5] He Dan, Jin Fengjun. An Analysis of the Spatio-temporal Impacts of Major Infrastructure on Real Estate Prices-Take Beijing Metro Line 4 as an Example. Journal of Beijing Union University (2013).

[6] Needham B. HURST, Sarah E. WEST. Public Transit and Urban Redevelopment: The Effect of Light Rail Transit on Land Use in Minneapolis, Minnesota. Regional Science and Urban Economics (2015).

[7] Zheng Siqi, Hu Xiaoke, Zhang Bo, Wang Shouqing. Urban Rail Transit's Value-Added Capture: From Theoryt to Reality. Urban Development Studies (2014).

[8] Lung-Feng Chien, Tsung-Yu Lai. A Study of Land Development Mechanism Incorporated with MRT Station Based on the Perspective of Sustainable Spatial Structure and Financial Cost: An Interpretation Based on the Zone Expropriation. Journal of Geographical Research (2012).

[9] Rachna G. Framework for Structuring Public Private Partnerships in Railways. Transport Policy (2014). 